OPEN ACCESS

Edited by:

Pia Giovannelli,

University of Campania Luigi Vanvitelli,

Reviewed by:

Teresita Padilla-Benavides, Wesleyan University, United States Gabriella Castoria, Second University of Naples, Italy Angel Matias Sanchez, CONICET Instituto de Medicina y

Biologia Experimental de Cuyo (IMBECU), Argentina

*Correspondence: Ignacio Camacho-Arroyo camachoarroyo@gmail.com

Specialty section: This article was submitted to Cancer Endocrinology, a section of the journal Frontiers in Endocrinology

Received: 11 December 2020 Accepted: 08 March 2021 Published: 26 March 2021

Citation: Bello-Alvarez C, Moral-Morales $A D$, González-Arenas $A$ and Camacho-Arroyo I (2021) Intracellular Progesterone Receptor and cSrc Protein Working Together to

Regulate the Activity of Proteins Involved in Migration and Invasion of Human Glioblastoma Cells.

Front. Endocrinol. 12:640298. doi: 10.3389/fendo.2021.640298

\section{Intracellular Progesterone Receptor and cSrc Protein Working Together to Regulate the Activity of Proteins Involved in Migration and Invasion of Human Glioblastoma Cells}

\author{
Claudia Bello-Alvarez ${ }^{1}$, Aylin Del Moral-Morales ${ }^{1}$, Aliesha González-Arenas ${ }^{2}$ \\ and Ignacio Camacho-Arroyo ${ }^{1 *}$ \\ 1 Unidad de Investigación en Reproducción Humana, Instituto Nacional de Perinatología-Facultad de Química, Universidad \\ Nacional Autónoma de México (UNAM), Ciudad de México, Mexico, ${ }^{2}$ Departamento de Medicina Genómica y Toxicología \\ Ambiental, Instituto de Investigaciones Biomédicas, UNAM, Ciudad Universitaria, Ciudad de México, Mexico
}

Glioblastomas are the most common and aggressive primary brain tumors in adults, and patients with glioblastoma have a median survival of 15 months. Some alternative therapies, such as Src family kinase inhibitors, have failed presumably because other signaling pathways compensate for their effects. In the last ten years, it has been proven that sex hormones such as progesterone (P4) can induce growth, migration, and invasion of glioblastoma cells through its intracellular progesterone receptor (PR), which is mostly known for its role as a transcription factor, but it can also induce non-genomic actions. These non-classic actions are, in part, a consequence of its interaction with cSrc, which plays a significant role in the progression of glioblastomas. We studied the relation between PR and cSrc, and its effects in human glioblastoma cells. Our results showed that P4 and R5020 (specific PR agonist) activated cSrc protein since both progestins increased the p-cSrc (Y416)/cSrc ratio in U251 and U87 human glioblastoma derived cell lines. When siRNA against the PR gene was used, the activation of cSrc by P4 was abolished. The co-immunoprecipitation assay showed that cSrc and PR interact in U251 cells. P4 treatment also promoted the increase in the p-Fak (Y397) (Y576/577)/Fak and the decrease in p-Paxillin (Y118)/Paxillin ratio, which are significant components of the focal adhesion complex and essential for migration and invasion processes. A siRNA against cSrc gene blocked the increase in the p-Fak (Y576/Y577)/Fak ratio and the migration induced by $\mathrm{P} 4$, but not the decrease in $\mathrm{p}$-Paxillin (Y118)/Paxillin ratio. We analyzed the potential role of cSrc over PR phosphorylation in three databases, and one putative tyrosine residue in the amino acid 87 of PR was found. Our results showed that P4 induces the activation of cSrc protein through its PR. The latter and cSrc could interact in a bidirectional mode for regulating the activity of proteins involved in migration and invasion of glioblastomas.

Keywords: glioblastoma, progesterone receptor, cSrc, non-genomic actions, focal adhesion kinase, paxillin 


\section{INTRODUCTION}

Astrocytomas are the most common primary brain tumors in the central nervous system (CNS). The WHO classifies these tumors according to the degree of malignancy in a range from I to IV. Grade IV represents the most malignant astrocytoma, also known as glioblastoma (1). Patients with glioblastoma have an overall survival of 15 months, even when receiving the standard therapy consisting of the maximum bearable surgical removal followed by radiotherapy and chemotherapy with temozolomide (2). The current standard treatment for glioblastoma has remained unchanged for more than ten years (3). Some alternatives, such as the use of angiogenesis blockers or Src family kinase inhibitors, have been tested in clinical assays, but none of them with successful outcomes $(4,5)$ The poor prognosis of patients with glioblastoma is a consequence of the high rate of recurrence of these tumors promoted by the inherently radioresistance and chemo-resistance and the high rate of migration and tumor invasion cells (6). Glioblastoma cells can spread to the surrounding brain parenchyma, which makes extremely difficult the complete resection of the tumor, and finally provokes the recurrence of glioblastoma (7).

Migration and invasion of tumor cells to the normal brain are complex processes that involve multiple steps and molecular signaling. In this context, the focal adhesion complex has a significant role. Some of their structural and regulator components, including non-receptor cytoplasmic tyrosine kinase cSrc, Focal adhesion kinase (Fak), Paxillin (Pax), Tyrosine-protein phosphatase non-receptor type 12 (PTP-PEST), and integrins have been associated with the spread of glioblastoma cells $(8-11)$. The tyrosine kinase Fak acts as a regulator and scaffold protein since it can recruit cSrc and Pax to the specific sites in the focal adhesion complex. In turn, cSrc can phosphorylate other proteins, including Fak and Pax to form an active complex able to mediate the cellextracellular matrix (ECM) adhesion, protrusion of cytoplasm to form the leading edge, cell contraction, recruitment of proteases, and detachment of the trailing edge (12). The role of PTP-PEST in glioblastomas has been associated with the stability of focal adhesion substrates (Fak, Pax, among others) by the regulation of their phosphorylation-dependent ubiquitination (11).

Lewis-Tuffin and colleagues demonstrated that some Src Family Kinase members, such as cSrc, Fyn, Yes, and Lyn, have an essential role in the motility of glioblastoma cells since the knockdown of these kinases reduces the rate of migration in three different cell lines (8). Some stem cell markers, such as Oct$3 / 4$ have been related to increased migration and invasion of glioma stem cells through cSrc and Fak upregulation (13).

As a result of the higher prevalence of glioblastoma in men than women (14), sex hormones and their receptors have gained particular attention. Several studies have demonstrated a central role of progesterone (P4) in the promotion of proliferation (15,

Abbreviations: CNS, central nervous system; Fak, Focal adhesion kinase; Pax, paxillin; ECM, extracellular matrix; PTP-PEST, (tyrosine-protein phosphatase non-receptor type 12); TCGA, The Cancer Genome Atlas; P4, progesterone; PR, progesterone receptor; SFK, Src Family Kinase; ER, estrogen receptor, mPRs, membrane progesterone receptors; PAQR, Progestin and AdipoQ Receptor.
16), migration, and invasion (17) of glioblastoma cells. One of the proteins with a great affinity for $\mathrm{P} 4$ is the progesterone receptor (PR), which belongs to the nuclear receptor family, and acts as a ligand-inducible transcription factor (18). When oligonucleotide antisense against PR or RU486, an antagonist of PR, was administered, the effect of P4 over migration and invasion on human glioblastoma cells was significantly diminished (17). These results suggest that PR has a significant role in promoting the progression of glioblastomas. In some breast cancer cell lines, it has been proven that $\mathrm{P} 4$ activates cSrc through $\mathrm{PR}$, and in turn, increases migration and invasion rate (19). However, the role of PR in cSrc activation and their participation in the migration and invasion of glioblastoma cells is unknown. In this work, we studied the interplay between PR and $\mathrm{cSrc}$, and its effects on the activity of proteins involved in migration and invasion of glioblastoma cells. To study the potential relationship between these proteins, glioblastoma-derived cell lines were treated with P4 or R5020 (PR agonist), and the phosphorylated/non-phosphorylated ratio of cSrc was measured by western blot. P4 and R5020 increased cSrc phosphorylation. To confirm the participation of $\mathrm{PR}$ in the cSrc phosphorylation, cells were transfected with a commercial siRNA against PR. Cells transfected with the PR siRNA were unable to increase cSrc phosphorylation. To investigate the physical interaction between PR and cSrc, we performed a coimmunoprecipitation assay, and interaction between PR and cSrc was observed. In silico analysis showed that cSrc could participate in the phosphorylation of $\mathrm{PR}$ in the amino acid 87. The role of cSrc activation by $\mathrm{P} 4$ in the switch Fak-phosphofak and Pax-phosphopax ratios and the migratory capacity of glioblastoma cells was determined by western blot and woundhealing assay in cells transfected with a commercial siRNA against cSrc. Fak phosphorylation and migration decreased in cells transfected with siRNA against cSrc compared to cells treated with control siRNA. Findings of this work suggest for the first time that cSrc and PR interact in glioblastoma cells. P4 through PR induces cSrc activation, which in turn participates in regulating the activity of proteins involved in the migration and invasion of glioblastomas.

\section{MATERIALS AND METHODS}

\section{Cell Culture and Treatments}

U251 and U87 (ATCC, USA) human glioblastoma derived cell lines were plated in $10 \mathrm{~cm}$ dishes and sustained in DMEM medium (In vitro, S.A., D.F., MEX), supplemented with $10 \%$ fetal bovine serum (FBS), $1 \mathrm{mM}$ pyruvate, $2 \mathrm{mM}$ glutamine, $0.1 \mathrm{mM}$ non-essential amino acids (GIBCO, NY, USA) at $37^{\circ} \mathrm{C}, 5 \% \mathrm{CO} 2$. The culture medium mentioned above was replaced by DMEM medium (In vitro, S.A., CDMX., MEX) without phenol red and free of hormones, supplemented with charcoal-stripped serum FBS (sFBS) (Hyclone, Utah), $24 \mathrm{~h}$ before the treatments. Cells were treated with P4 (10, 50 and $250 \mathrm{nM}), 10 \mathrm{nM}$ of R5020 (progestin with high affinity for $\mathrm{PR}(\mathrm{Kd} \approx 2 \mathrm{nM}))(20)$ or vehicle (DMSO 0.001\%). Cell treatments lasted 10 and $20 \mathrm{~min}$ to assess cSrc, Fak, and Pax phosphorylation. 


\section{Protein Extraction and Western Blotting}

Activation of cSrc, Fak, and Pax was determined by measuring protein phosphorylation. Cells were treated with $\mathrm{P} 4(10,50$, and $250 \mathrm{nM}$ ), R5020 (10 nM), or vehicle (DMSO 0.001\%), and western blot was used to determine the content of p-cSrc, pFak, and p-Pax. After treatments, cells were homogenized in RIPA buffer with a cocktail of protease inhibitors (Sigma Aldrich, St Louis, MO USA, \# P8340) and a group of phosphatase inhibitors $\left(\mathrm{NaF}, \mathrm{Na}_{4} \mathrm{P}_{2} \mathrm{O}_{7}\right.$, and $\mathrm{Na}_{3} \mathrm{VO}_{4}$ ). Proteins were obtained by centrifugation at $12,500 \mathrm{rpm}$ for $5 \mathrm{~min}$ and quantified using the NanoDrop-2000 spectrophotometer (Thermo Scientific, MA, USA). For protein separation, $30 \mu \mathrm{g}$ were loaded on a polyacrylamide gel at a concentration of $8.5 \%$ for cSrc and Pax, and 7.5\% for Fak, under denaturing conditions. Proteins were transferred to a nitrocellulose membrane under semi-dry conditions in a transfer (BIO-RAD) for $30 \mathrm{~min}$ at $25 \mathrm{~V}$ in the case of the $60 \mathrm{kDa}(\mathrm{cSrc})$ and $68 \mathrm{kDa}(\mathrm{Pax})$ proteins and $1 \mathrm{~h}$ at $25 \mathrm{~V}$ in the case of the $125 \mathrm{kDa}$ protein (Fak). Blocking was performed with $5 \%$ bovine serum albumin at $37^{\circ} \mathrm{C}$ for $2 \mathrm{~h}$. Membranes were incubated with the primary antibodies against the phosphorylated and total forms of the cSrc, Pax, and Fak proteins (phospho Src Tyr-416 Cell Signaling, MA, USA, Ref. 2101; Src Cell Signaling, MA, USA. USA, Ref. 2108; phospho Pax Tyr-118 Cell Signaling, MA, USA, Ref. 2541; Pax Cell Signaling, MA, USA, Ref. 2542; phospho Fak Tyr-397 Cell Signaling, MA, USA, Ref. 3283; Fak Cell Signaling, MA, USA, Ref. 3285). Antibodies against the total and phosphorylated forms were used in a 1/500 dilution. As a loading control, the alphatubulin protein was detected at a 1/1,000 dilution (Santa Cruz Biotechnology, St. Louis, TX, USA, Ref. sc-398103). All the antibodies were incubated for $48 \mathrm{~h}$ except that against alphatubulin, which was incubated for $24 \mathrm{~h}$. Subsequently, the membranes were incubated with the secondary antibody against rabbit (Thermo Scientific, USA, Ref. 1858415) or mouse (Santa Cruz Biotechnology, TX, USA, Ref. sc-516102) $(1 / 10,000)$ with shaking and at room temperature for $45 \mathrm{~min}$. The primary and secondary antibodies were removed from the membranes with a solution containing Tris- $\mathrm{HCl} \mathrm{pH} 6.8$ at 0.06 $\mathrm{M}, \mathrm{SDS}$ at $2 \%$, and $\beta$-mercaptoethanol at $0.7 \%$ for $30 \mathrm{~min}$ at $50^{\circ} \mathrm{C}$ at stirring. The chemiluminescent signal was detected by exposing the membranes to the SuperSignal West Fento substrate (Thermo Scientific \# 34096) with Kodak Biomax Light Film plates (Sigma-Aldrich, MO, USA).

\section{siRNA Transfection}

Commercial siRNA against PR was used to test if P4 induced the cSrc activation through its PR. Briefly, $2.5 \times 10^{5}$ U251 cells were plated in 6-well dishes in DMEM medium supplemented with $10 \% \mathrm{FBS}$, and $24 \mathrm{~h}$ later, the medium was replaced with DMEM phenol red-free medium without FBS and antibiotics. Cells were transfected with a PR siRNA $(100 \mathrm{nM})$ or with control siRNA that does not induce specific mRNA degradation using Lipofectamine RNAiMAX (Thermo Scientific, USA). The medium was refreshed $12 \mathrm{~h}$ after the addition of a PR siRNA or control siRNA, and $48 \mathrm{~h}$ after siRNAs addition, the cells were harvested for total RNA extraction to determine the efficiency of the transfection. The same protocol was used with Commercial siRNA against cSrc to test the interplay between P4, cSrc, and Fak and Pax activation. In this case, the efficiency of transfection was determined by western blot, and $48 \mathrm{~h}$ after transfection, the cells were harvested for protein extraction as previously described.

\section{RNA Extraction and RT-PCR}

RNA extraction was performed using TRIzol reagent (Invitrogen, USA) and following the manufacturer's instructions. One $\mu \mathrm{g}$ of total RNA was used to synthesize the first-strand cDNA in a reaction carried out by M-MLV reverse transcriptase (Thermo Scientific, USA) following the manufacturer's protocol. The efficiency of transfection was determined by RT-PCR from $2 \mu \mathrm{l}$ of synthesized cDNA. PCR conditions were: $5 \mathrm{~min}$ incubation at $94^{\circ} \mathrm{C}$ followed by 28 cycles of $15 \mathrm{~s}$ at $94^{\circ} \mathrm{C}, 30 \mathrm{~s}$ at $60^{\circ} \mathrm{C}$, and $30 \mathrm{~s}$ at $68^{\circ} \mathrm{C}$, and a final incubation for $60 \mathrm{~s}$ at $68^{\circ} \mathrm{C}$. The $18 \mathrm{~S}$ ribosomal RNA gene was used as an internal expression control. The primers used were PR forward 5'-CCCGCCCTATCTCAACTACC-3' and reverse 5'GTTGTGCTGCCCTTCCATTTG-3'). 18S forward 5'AGTGAAACTGCAATGGCTC-3' and reverse 5' TGACCGGGTTGGTTTTGAT-3’.

\section{Migration Assay}

The wound-healing assay was performed to determine the cell migration of U251 cells. $2.5 \times 10^{5}$ cells were plated in 6-well slides with DMEM high glucose supplemented until reaching $70 \%$ confluence. Then, cells were transfected as was described in the previous section. About $48 \mathrm{~h}$ after transfection and in $90 \%$ of confluence, a scratch was made using a $200 \mu$ pipette tip. Floating cells were removed with PBS and DMEM medium (In vitro, S.A., CDMX., MEX) without phenol red and free of hormones, supplemented with $10 \%$ SFB also free of hormones were added again. Cytosine $\beta$-D-arabinofuranoside hydrochloride (10 $\mu \mathrm{M}$, Ara-C, C1768, Sigma-Aldrich, St. Louis, MO, USA) was used to inhibit cell proliferation $1 \mathrm{~h}$ before adding the treatments. Cells were treated with $\mathrm{P} 4(50 \mathrm{nM})$, or vehicle (DMSO 0.001\%). Four random fields were chosen per treatment to determine cell migration after 0,6 , and $12 \mathrm{~h}$ of treatment. Photographs were taken with an Infinity 1-2C camera (Lumenera, CA) connected to the inverted microscope Olympus CKX41 (Olympus, JPN).

\section{Co-Immunoprecipitation}

Cell cultures were lysed in a buffer containing $50 \mathrm{mM}$ Tris- $\mathrm{HCl}$ (pH 7.4), $150 \mathrm{mM} \mathrm{NaCl}, 1 \mathrm{mM}$ EDTA, 1\% Triton X-100, 0.1\% SDS, and a cocktail of protease inhibitors (Sigma Aldrich, St. Louis, MO USA, \# P8340) at $4^{\circ} \mathrm{C}$ overnight. Cell lysates were centrifuged at $12,500 \mathrm{rpm}$ for $15 \mathrm{~min}$. One $\mathrm{mg}$ of total protein present in the supernatant was incubated with $2 \mu \mathrm{g}$ of antibody anti-PR (Santa Cruz Biotechnology Dallas, Texas, USA Ref B-30 sc-811) and $50 \mu \mathrm{L}$ of sepharose-coupled protein A/G plusagarose (sc-2003; Santa Cruz Biotechnology) under permanent agitation at $4^{\circ} \mathrm{C}$ overnight. The next day, samples were centrifuged, and the pellets washed three times with buffer $(20$ $\mathrm{mM}$ Tris $\mathrm{HCl} ; 150 \mathrm{mM} \mathrm{NaCl}$; $1 \mathrm{mM}$ EDTA, 0.1 Triton X-100, 
and a cocktail of protease inhibitors (Sigma Aldrich, St. Louis, MO USA, \# P8340 pH 7.5). Finally, the samples were denatured by boiling in loading buffer (120 mM Tris, pH 6.8; $4 \%$ SDS; $0.2 \%$ glycerol; $5 \% \quad \beta$-mercaptoethanol; and $10 \mathrm{mg} / \mathrm{ml}$ bromophenol blue) and separated in SDS-PAGE. Western blot for cSrc was done as previously described in the Protein extraction and Western blotting section.

\section{TCGA Data Analysis}

RNA-Seq counts from 196 grade II, 223 grade III, and 139 grade IV gliomas were obtained from Glioblastoma and Low-Grade Glioma projects of The Cancer Genome Atlas (TCGA) repository (https://portal.gdc.cancer.gov/). The data were downloaded and processed using TCGAbiolinks package version 2.12.6 for R.17 Additionally, expression profiles of 249 healthy brain cortex samples were obtained from the GTEx database (https://gtexportal.org/home/). Data were normalized by DESeq2 version 1.22.2 and plotted. Gene expression correlation in glioblastoma, from the TCGAbiolinks package for R.

\section{Statistical Analysis}

Data were and analyzed using Graph Pad Prism 5 program (GraphPad Software, Inc., USA). A one-way ANOVA with Bonferroni post hoc test (Figures 1A, E, F, 2C-E, 3B) or tstudent test were used to establish the statistical differences between comparable groups. Values of $\mathrm{p}<0.05$ were considered statistically significant.

\section{RESULTS}

\section{Activation of cSrc by P4 Is Mediated by PR in Glioblastoma Cells}

The role of PR and cSrc in breast cancer has been broadly studied. The stimulation of breast cancer cells with P4 activated cSrc through PR, and induced various signaling pathways that conducted to cancer progression (21-23). To test the potential role of $\mathrm{P} 4$ in cSrc activation in glioblastoma cells, at the beginning of the study, a time-dependence assay (0-60 min) using P4 (10 nM) was performed in U251 cells (Supplementary Figure 1), however, a significant effect on $\mathrm{p}$-cSrc/cSrc ratio was not observed, and we decided to test higher P4 concentrations, at 10 (Figures 1A, B) and $15 \mathrm{~min}$ (Supplementary Figure 2). U251, and U87 cells were treated with three different concentrations of $\mathrm{P} 4$ (10, 50 and, $250 \mathrm{nM})$ for $10 \mathrm{~min}$, and the phosphorylation of cSrc (Y416) was determined by western blot. P4 induced cSrc activation at $50 \mathrm{nM}$ in U251 and U87 cells (Figures 1A, B). P4 has affinity for other receptors besides PR $(24,25)$; Nevertheless, because of the high affinity of R5020 for $\mathrm{PR}(\mathrm{Kd} \approx 2 \mathrm{nM})(20)$ over other receptors (AR 1\% binding affinity) (26-28), cells were also treated with $10 \mathrm{nM}$ of R5020. As in the case of P4, R5020 increased the p-cSrc (Y416)/cSrc ratio in U251 and U87 cells (Figures 1C, D). To finally demonstrate that cSrc activation by $\mathrm{P} 4$ was mediated by its intracellular PR, U251 cells were transfected with a commercial siRNA against PR or control siRNA (scramble sequence) and treated with $\mathrm{P} 4$ for 10 min at $50 \mathrm{nM}$. The efficiency of transfection was higher than $50 \%$ (Figure 1E). P4 induced the activation of $\mathrm{cSrc}$ in cells with control siRNA as in the previous experiments. In contrast, the siRNA against PR blocked the increase in $\mathrm{p}$-cSrc (Y416)/cSrc ratio induced by $\mathrm{P} 4$ (Figure 1F). This result demonstrates the participation of $\mathrm{PR}$ in the $\mathrm{cSrc}$ activation by $\mathrm{P} 4$ (Figure 4). Considering the short time (10 $\mathrm{min}$ ) for the activation of $\mathrm{cSrc}$, this result suggests that $\mathrm{PR}$ exerts this effect through nongenomic actions.

\section{cSrc and PR Interact in U251 Cells}

Non-genomic actions of PR are associated with the polyproline domain which can interact with $\mathrm{SH} 3$ domains of a variety of proteins including cSrc. In breast cancer cell lines, a physical interaction between $\mathrm{cSrc}$ and PR has been demonstrated (22). Co-immunoprecipitation assay was performed to evaluate the interaction between PR and cSrc. U251 cells were immunoprecipitated with antibodies against $\mathrm{PR}$, and a western blot was carried out. In both vehicle and P4 treated cells, a band corresponding to $\mathrm{cSrc}$ was detected, indicating that PR (isoforms $\mathrm{A}$ and B) and cSrc directly or indirectly interact in glioblastoma cells. The treatment with $\mathrm{P} 4$ increased the interaction between $\mathrm{PR}$ and cSrc (Figure 1G). This result suggests that activation of cSrc is possible because of the physical interaction between cSrc and PR in glioblastoma cells (Figure 4).

\section{P4 Induces a Switch in Fak-Phosphofak and Pax-Phosphopax Ratios Through cSrc in Glioblastoma Cells}

Fak and Pax are two of the most critical components of the focal adhesion complex, fundamental to regulating cell migration and invasion. To test if $\mathrm{P} 4$ was able to induce Fak and Pax activation, U251 and U87 cells were treated with P4 at $50 \mathrm{nM}$ for $20 \mathrm{~min}$, and their phosphorylation was determined by western blot. P4 (50 nM) increased the p-Fak/Fak ratio (Y397 and Y576/577) in U251 cells and the p-Fak/Fak ratio (Y576/577) in U87 cells, while in the case of Pax, P4 decreased the p-Pax/Pax ratio (Y118) in U251 cells at $20 \mathrm{~min}$ (Figures 2A, B). cSrc is one of the major kinases implicated in the phosphorylation of focal adhesion complex components, especially Fak (29). To test the role of cSrc in the phosphorylation of Fak and Pax, U251 cells were transfected with a commercial siRNA against cSrc or control siRNA (scramble sequence) and treated with P4 (50 nM) for $20 \mathrm{~min}$. The efficiency of transfection was $50 \%$ (Figure 2C). The siRNA against cSrc blocked the increase in the p-Fak/Fak (Y576/ 577) ratio induced by $\mathrm{P} 4$ (Figure 2D), but not the decrease in $\mathrm{p}$ $\mathrm{Pax} / \mathrm{Pax}$ ratio (Figure 2E). This result indicates that $\mathrm{P} 4$ is involved in regulating focal adhesion complex through $\mathrm{PR}$ and cSrc in glioblastoma cells (Figure 4).

\section{Silencing of cSrc Reduces the Migration Induced by P4}

Previous results suggest that $\mathrm{P} 4$ and $\mathrm{cSrc}$ have a fundamental role in the migration of glioblastoma cells, which in turn, participate in the recurrence of this tumor $(17,30)$. To determine whether 
A

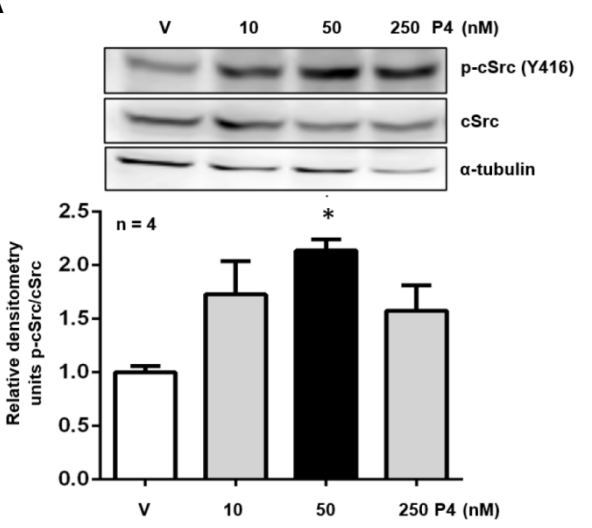

C

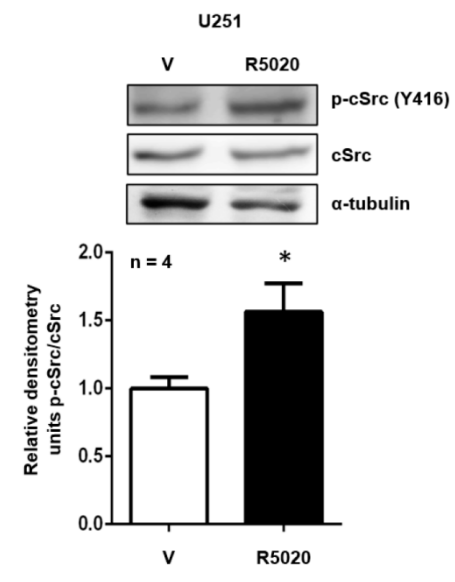

B

U87
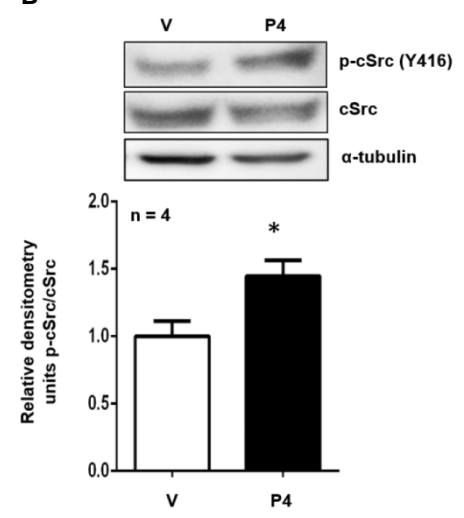

D
E

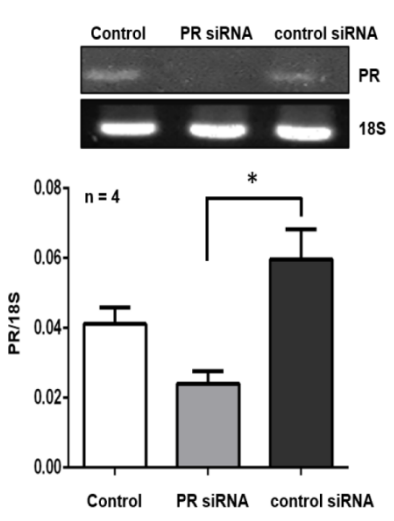

F
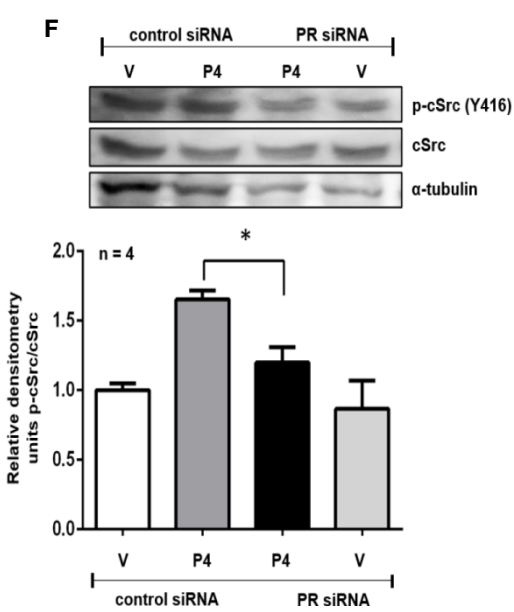

G

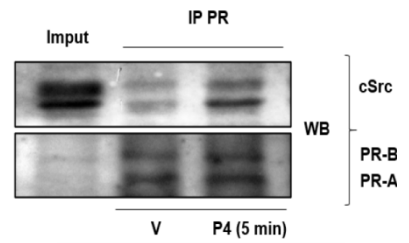

V P4 $(5 \mathrm{~min})$

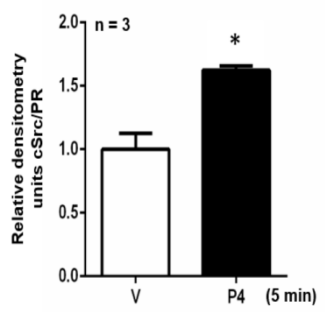

FIGURE 1 | P4 induces the activation of cSrc through PR. (A, B) U251 and U87 cells were treated with P4 (10, 50 and 250 nM) and P4 (50 nM) respectively or vehicle (V, DMSO 0.01\%) for 10 min. (C, D) U251 and U87 cells were treated with R5020 (10 nM) or vehicle (V, DMSO $0.01 \%)$ for 10 min. (E) U251 cells were transfected with PR siRNA and a control siRNA (an aleatory RNA sequence) (100 nM) or were only treated with lipofectamine (Control). (F) Transfected cells with PR siRNA or control siRNA were treated with P4 (50 nM) or vehicle $(V$, DMSO 0.01\%) for 10 min. Upper panels show the representative western blots for p-cSrc, cSrc, and $\alpha$-tubulin or representative RT-PCR bands for PR and 18S mRNA. Lower panels show the densitometric analysis. (G) U251 cells were treated with P4 (50 nM) or vehicle (V, DMSO 0.01\%) for 5 min and co-immunoprecipitated with PR. Data were normalized respect to the vehicle or control. Results are expressed as the mean \pm S.E.M. (A-F) $n=4$ (G) $n=3 ;{ }^{*} p<0.05$. 

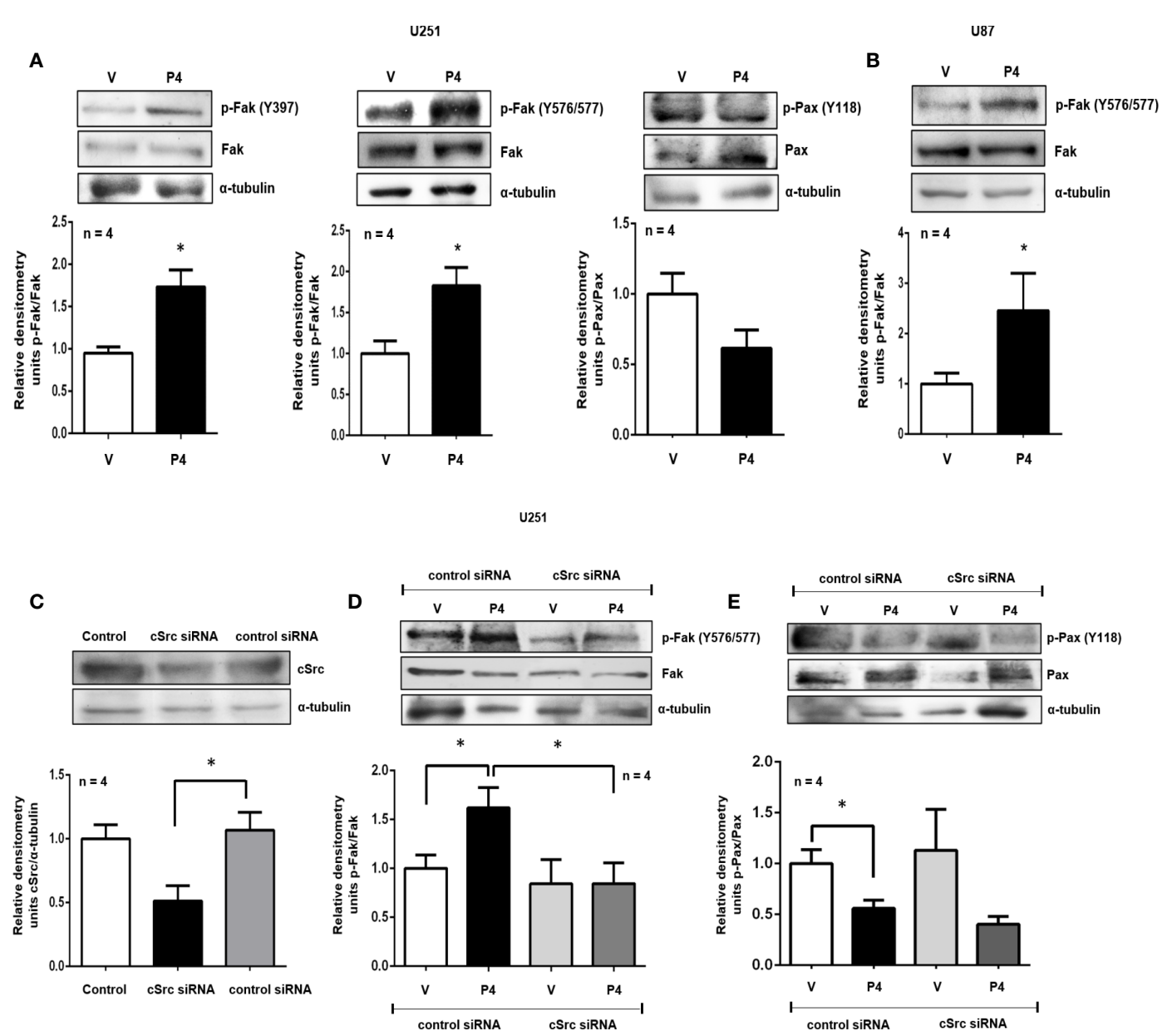

FIGURE 2 | P4 induces the activation of Fak and Pax through cSrc in glioblastoma cells. (A, B) U251 and U87 cells were treated with P4 (50 nM) or vehicle (V, DMSO $0.01 \%$ ) for $20 \mathrm{~min}$. (C) U251 cells were transfected with cSrc siRNA and a control siRNA (an aleatory RNA sequence) (100 nM) or were only treated with lipofectamine (Control). (D, E) Transfected cells with cSrc siRNA or control siRNA were treated with P4 (50 nM) or vehicle (V, DMSO $0.01 \%)$ for 20 min. Upper panels show the representative western blots for, cSrc, p-Fak, Fak, p-Pax, Pax, and $\alpha$-tubulin. Lower panels show the densitometric analysis. Data were normalized respect to the vehicle or control. Results are expressed as the mean \pm S.E.M. $n=4 ;{ }^{*} p<0.05$.

silencing of cSrc modify the migration induced by P4 in U251 cells, a scratch-wound assay was performed. In cells transfected with control siRNA and treated with P4, a slight increase in migration was observed as compared to vehicle at 6 and $12 \mathrm{~h}$ after treatment. This increase was inhibited in cells transfected with cSrc siRNA (Figures 3A, B). This result demonstrates that the migration of glioblastoma cells induced by $\mathrm{P} 4$ is related to the activation of $\mathrm{cSrc}$ and reinforces the previous molecular findings.

\section{cSrc Has Several Putative Phosphorylation Sites Over PR}

Phosphorylation of nuclear receptors, including PR, has great relevance in functions executed by these proteins. PR phosphorylation has been broadly studied in serine residues; however, there is scarce information about tyrosine residues. The potential role of active cSrc over PR phosphorylation was determined using three different databases (NetPhos 3.1, KinasePhos, and GPS 5.0). We found the same putative tyrosine residue in the amino acid 87 of PR in all of them. In the GPS 5.0 database, this residue presented the highest score, which means that it also has the highest potential for phosphorylation (Table 1). Even when this result must be confirmed in experimental assays, the information obtained by the databases opens the possibility of future investigation of functions and regulation of $\mathrm{PR}$ by $\mathrm{cSrc}$ phosphorylation (Figure 4).

\section{PXN (Pax) and PTPN12 (PTP-PEST) Expression Depends on Tumor Grade and Glioblastoma Subtype}

PXN and PTPN12 expression data from 196 grade II, 223 grade III, and 139 grade IV (glioblastoma) astrocytomas were obtained from TCGA and compared to 249 healthy human brain cortex samples from the GTEx database. The expression of these genes was also compared among the four subtypes of glioblastomas defined by Verhaak and colleagues (31). The PXN and PTPN12 mRNA expression increased in glioblastomas compared to normal brain, 

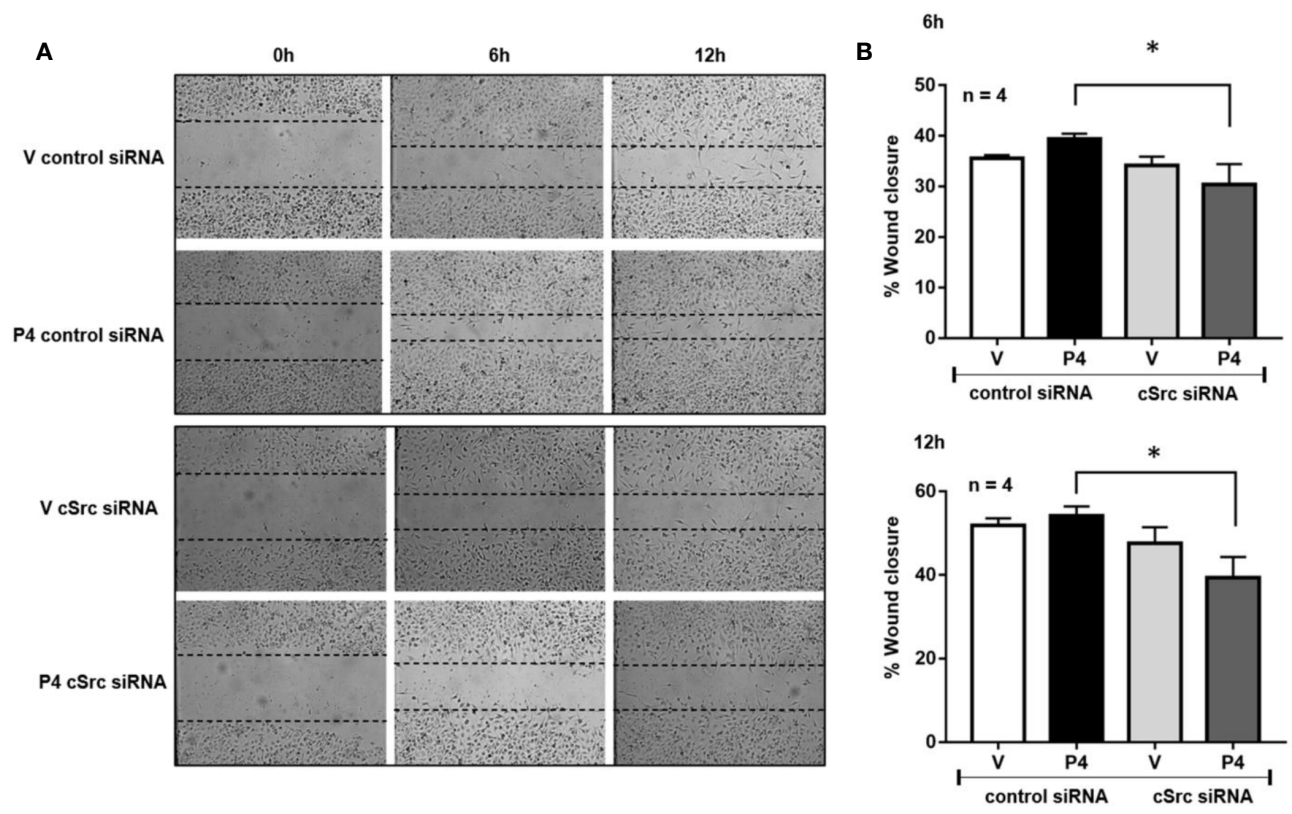

FIGURE 3 | cSrc participates in cell migration induced by P4. U251 cells transfected with cSrc siRNA and a control siRNA (an aleatory RNA sequence) (100 nM) were treated with P4 (50 nM) or vehicle (V, DMSO 0.01\%) in cells. Photographs from the scratch area were taken at 0, 6 and $12 \mathrm{~h}$ and were captured with 400x magnification. (A) Representative image of the scratch area. (B) Graph of the wound closure (\%), determined in the scratch area. Results are expressed as the mean \pm S.E.M. $n=4 ;{ }^{*} p<0.05$.

and in the case of PTPN12, the expression was higher in glioblastomas compared to astrocytomas grades II and III (Supplementary Figure 3A). The analysis of expression among the four subtypes of glioblastomas showed that PXN and PTPN12 have the highest levels of expression in the mesenchymal subtype (the most aggressive glioblastoma subtype) (32) (Supplementary Figure 3A). The analysis of gene expression correlation between PXN and PTPN12 revealed a value of 0.61 (significant positive correlation) (Supplementary Figure 3B).

\section{DISCUSSION}

Glioblastoma is the most malignant brain tumor. Patients with glioblastoma have an overall survival of 14 months (1). One of the main influencing factors in the poor prognosis of these patients is the high capacity of glioblastoma cells to migrate and invade the brain parenchyma surrounding the tumor, which in turn makes extremely difficult a complete surgical resection (33). Several molecular signals are implicated in the processes of migration and invasion in glioblastoma; some are activated by cSrc kinase protein that belongs to the Src Family Kinase (SFK) $(8,34)$. Of all of the other family members (FYN, YES, BLK, YRK, FGR, HCK, LCK, and LYN) cSrc is the most often associated with cancer progression (35). This kinase has been associated with migration and invasion of multiple malignancies through the regulation of actomyosin contraction, actin polymerization (36), and ECM proteolysis (37). In glioblastomas, SFKs play an essential role in events related to motility and disruption of ECM.
It has been demonstrated that $\mathrm{PR}$ activated by $\mathrm{P} 4$ promotes the migration and invasion of glioblastoma cells (17). However, there is no information about the possible interplay between PR and cSrc in glioblastoma cells. In this work, we first investigated the capacity of P4 to activate cSrc through its PR and how this activation regulates the phosphorylation/dephosphorylation of kinases related to migration and invasion of glioblastoma cells. U251 and U87 cells were treated with P4 for $10 \mathrm{~min}$, and the activation of cSrc was evaluated by western blot. The most effective concentration of $\mathrm{P} 4$ was $50 \mathrm{nM}$. The increase in the $\mathrm{p}$-cSrc (Y416)/cSrc ratio in U251 cells was evident. Y416 is the amino acid residue localized in the domain $\mathrm{SH}$, which contains the autophosphorylation site required for the full cSrc activation (38). When U87 cells were treated with $\mathrm{P} 4$, a significant increase in the $\mathrm{p}-\mathrm{cSrc}(\mathrm{Y} 416) / \mathrm{cSrc}$ ratio was observed. Therefore, P4 induces the activation of cSrc in human glioblastoma derived cell lines.

In colorectal cancer, the increasing activity of $\mathrm{cSrc}$ rather than its overexpression is associated with metastasis $(39,40)$. cSrc is one of the first and most studied proto-oncogenes (41); however, its role in cancer progression is not entirely understood. The central role attributed to this kinase was increasing cellular proliferation (42). However, most recent investigations have found that $\mathrm{cSrc}$ regulates processes such as adhesion, invasion, and motility $(38,43)$. For example, the overexpression of cSrc in colon cancer does not induce the proliferation rate increase, but it facilitates the spread of cells (37). Some colleagues consider that cSrc induces cellular proliferation at the first stage of cancer development but regulates migration and invasion processes at the later stages (29). It has been demonstrated an essential role of 


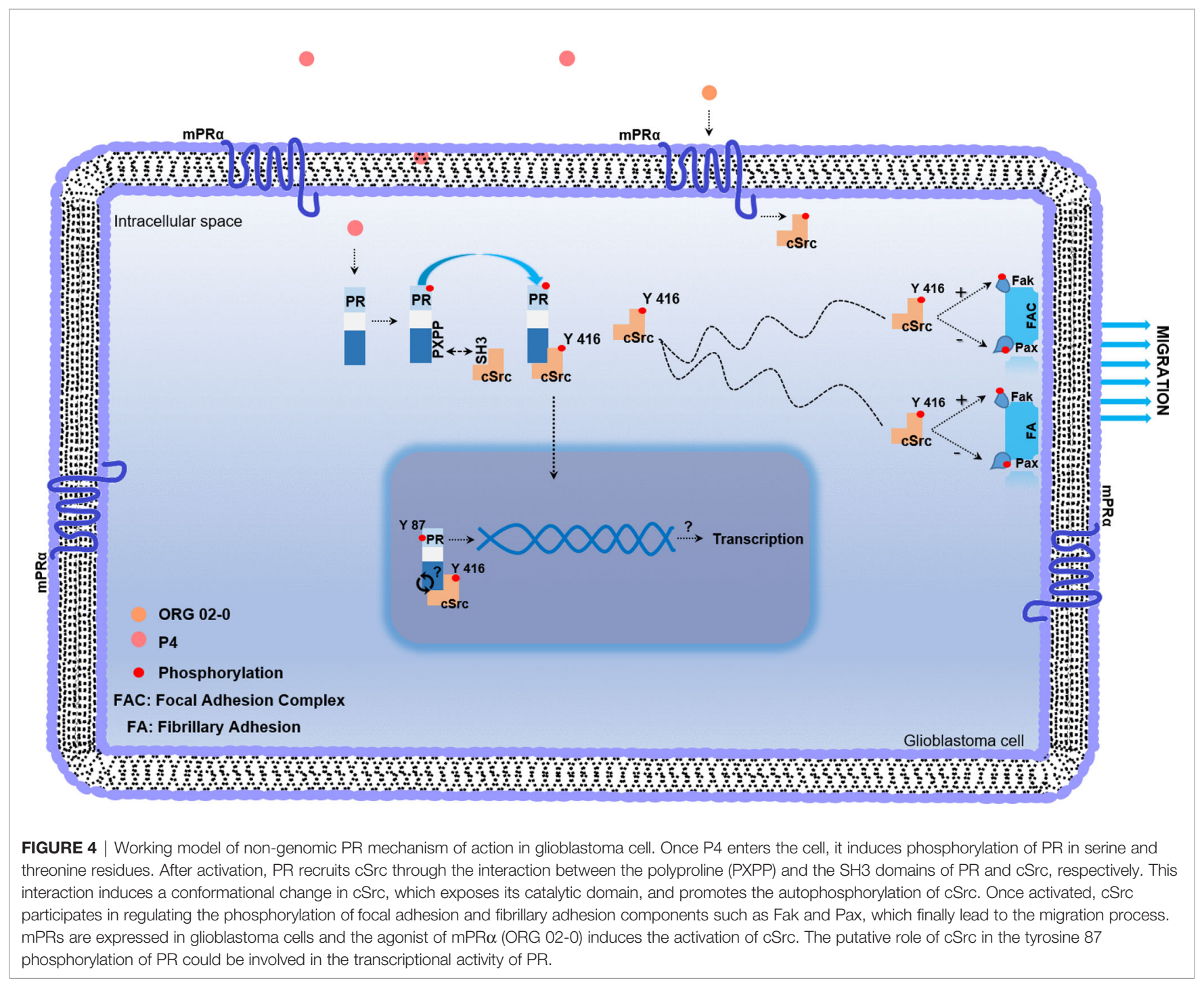

TABLE 1 | In silico analysis of putative phosphorylation sites of cSrc over PR.

\begin{tabular}{lccccccc}
\hline & ID & Position & AA & Kinase & Score & E-value & Peptide \\
\hline Netphos 3.1 & Progesterone Receptor Homo sapiens & 87 & $Y$ & SRC & 0.516 & \\
KinasePhos & AAA60081.1 & & EGFR & 0.444 & VEGAYSRAE \\
GPS 5.0 & & 87 & $Y$ & SRC & VEGAYSRAE & LSDVEAYSRAEATR
\end{tabular}

Three different databases to predict phosphorylation sites were used to analyze the potential role of cSrc in PR phosphorylation. One putative tyrosine residue in the amino acid 870 f PR was found in three databases: NetPhos 3.1, KinasePhos, and GPS 5.0.

SFKs in the motility of glioblastoma cells $(30,44)$. The activation of $\mathrm{cSrc}$ by $\mathrm{P} 4$ may be involved in the regulation of events associated with the migration and invasion of glioblastoma cells.

One of the first identified substrates of cSrc was Fak, a nonreceptor tyrosine kinase closely related to regulating a variety of cellular processes, including cell migration (45). At the focal adhesion complexes, cSrc induces Fak's phosphorylation and facilitates the turnover of these junctions, an essential step to cell migration. The complex Fak-cSrc can also phosphorylate Pax, which recruits other components to focal adhesion sites (38). It has been reported elevated levels of Fak expression in anaplastic astrocytoma and glioblastoma tumor biopsy samples compared to normal brain (46). In this work, we evaluated the capacity of P4 to activate Fak and Pax. P4 promoted the increase in the p-Fak(Y397)/ Fak and p-Fak(Y576/577)/Fak ratio that corresponds to the autophosphorylation site and to another site directly phosphorylated by cSrc, respectively. Thus, P4 induces Fak's phosphorylation, including in the tyrosine residues directly related to $\mathrm{cSrc}$ and with the turnover of focal adhesions (38). To determine if $\mathrm{P} 4$ induces the phosphorylation of Fak through $\mathrm{cSrc}$, we 
transfected U251 cells with a commercial siRNA against cSrc or with control siRNA and treated them with $\mathrm{P} 4$ in the same conditions of the previous experiments. In this case, $\mathrm{P} 4$ failed to induce Fak activation in cells transfected with siRNA against cSrc.

Pax is a multifunctional protein that plays a scaffolding role at focal adhesions. Overexpression of this protein has been associated with high-grade astrocytomas as well with a poor survival (10). Upon integrin activation, Pax is mainly phosphorylated at two different tyrosine residues, namely Y31 and Y118, but this phosphorylation state is not permanent. Zaidel-Bar and colleagues found that tyrosinephosphorylated Pax is associated with focal complex and focal adhesions, while non-phosphorylated Pax is associated with fibrillary adhesions. These colleagues proposed a hypothetical model in which Pax is initially phosphorylated and recruited to integrin adhesions. The rate of this recruitment is regulated by the presence of both phosphopax and Pax. Finally, phosphopax is dephosphorylated at a high rate under mechanical force, and the phosphorylation is reestablished at a low rate (47). In this work, we observed that $\mathrm{P} 4$ decreased the $\mathrm{p}-\mathrm{Pax}(\mathrm{Y} 118) / \mathrm{Pax}$ ratio in $\mathrm{U} 251$ cells 20 min after the treatment. This result suggests that $\mathrm{P} 4$ should induce Pax recruitment towards the integrins at fibrillary adhesions and contributes to the presence of both phosphorylated and unphosphorylated state, which is necessary to migration processes. When U251 cells were transfected with the siRNA against cSrc, the reduction in $\mathrm{p}-\mathrm{Pax}(\mathrm{Y} 118) / \mathrm{Pax}$ was more evident, which is in line with the role of cSrc in Pax phosphorylation. One of the proteins closely related to the dephosphorylation of Pax is the tyrosine phosphatase PTP-PEST. Shen and colleagues found that PTP-PEST coimmunoprecipitates with Fak and Pax in chicken embryo cells (48). These colleagues also demonstrated that the expression of PTPPEST decreases the phosphotyrosine on Pax (49). In glioblastoma, PTP-PEST regulates the invasion events by phosphorylationdependent ubiquitination of essential focal proteins such as Cas, Fak, Pax, and Src (11). Bioinformatic analysis revealed that PXN and PTPN12 mRNA expression was higher in astrocytomas (Grades II, III, and IV) compared to normal brain and showed the highest expression in the mesenchymal subtype (the most aggressive glioblastoma subtype, associated with bad prognostic) (32). The analysis of gene expression correlation revealed a value of 0.61 (significant positive correlation). These results suggest that these proteins together are implicated in the progression of glioblastomas. In the same line, the scratch-wound assay analysis showed that silencing of cSrc in U251 cells abolished the increase in cell migration induced by P4. Interestingly in 2013, Matias-Sanchez and colleagues found that PR, stimulated by $\mathrm{P} 4$ and the synthetic progestin medroxyprogesterone acetate, have an essential role in the actin polymerization, branching, and focal adhesion complex formation in cortical neurons. The molecular mechanism proposed by these colleagues involucrate the activation of Fak, and other proteins related to migration, such as WAVE and moesin. Phosphorylation of the latter was promoted by PR through the Ras homolog gene family, member A and Rho-associated kinase-2. Therefore, we should not underestimate the role of these last proteins in P4 effects (50).

The observed effects induced by $\mathrm{P} 4$ could also be mediated by membrane progesterone receptors (mPRs), G protein-coupled receptors that belong to the Progestin and AdipoQ Receptor Family (PAQR). Five subtypes of $\mathrm{mPRs}(\mathrm{mPR} \alpha, \mathrm{mPR} \beta, \mathrm{mPR} \delta$, $\mathrm{mPR} \epsilon$, and $\mathrm{mPR} \gamma$ ) have been identified, and they are expressed in human glioblastoma cells $(51,52)$. Importantly, the activation of $\mathrm{mPR} \alpha$ by ORG $02-0$, a specific $\mathrm{mPR} \alpha$ agonist, induces proliferation, migration, and invasion through the activation of cSrc and Akt in human derived glioblastoma cells (24).

P4 can exert its effects through various receptors in glioblastoma cells $(24,25)$. Therefore, an agonist of PR (R5020) was used to treat the U251 and U87 cells, and in both cases, an increase in p-cSrc (Y416)/cSrc ratio was observed. Considering the high affinity of R5020 for the PR and that this progestin is unable to be transformed into the active metabolites of P4 (53), it makes sense to think that results previously described are a consequence of the action of P4 through its PR and not by another receptor or metabolite. To determine if cSrc activation by $\mathrm{P} 4$ was induced through $\mathrm{PR}$, a more specific assay was conducted. U251 cells were transfected with a commercial siRNA against PR or with control siRNA and treated with P4 in the same conditions of the previous experiments. As is shown in Figure 1F, P4 failed to induce cSrc activation in cells transfected with siRNA against PR. Thereby, the effect of P4 over cSrc activation is mediated by PR in these human glioblastoma cells.

Even though PR is widely known for its role as a transcription factor $(53,54)$, in the last two decades the attention has been focused on the actions that it can exert out of the nucleus (55). Non-genomics actions of PR are due to a polyproline domain (amino acids 396456) that can interact with the $\mathrm{SH} 3$ domain of several proteins, including cSrc. Once this interaction occurs, the intramolecular interactions that hold cSrc in a closed configuration are disrupted, and the autophosphorylation site is exposed (22). This mechanism has been broadly studied in breast cancer. It has been demonstrated that in breast cancer cells, $\mathrm{P} 4$ can promote the interaction between $\mathrm{PR}$ and cSrc and, in turn, inducing proliferation (56), migration, and invasion (19). To test the interaction between PR and cSrc we performed a co-immunoprecipitation assay. This assay shows that $\mathrm{PR}$ (isoforms A and B) and cSrc interact in glioblastoma cells and that $\mathrm{P} 4$ enhances this interaction. This result suggests that activation of cSrc by $\mathrm{P} 4$ is due to a conformational change in cSrc that enables the autocatalytic domain to be exposed. However, this result must be interpreted with care since some colleagues have found that in breast cancer cell lines, the activation of cSrc through the PR is dependent on the estrogen receptor (ER). ER $\alpha$ plays an essential role in breast cancer cells by activating the Src/Erk pathway and increasing cell proliferation. Estrogens or progestins can induce this effect; however, according to studies conducted by Migliaccio and colleagues and Ballaré and colleagues, it is necessary to form a complex including $\mathrm{ER} \alpha, \mathrm{PR}$, and $\operatorname{Src}(21,23)$. Boonyaratanakornkit and colleagues, on the contrary, support the idea of PR selfsufficiency to induce cSrc activation without ER. They found that in breast cancer cells no expressing ER, P4 induced the activation of cSrc through PR (22). In glioblastomas, estradiol increased cell growth, migration, invasion, and the epithelialmesenchymal transition (EMT) through activation of ER $\alpha$ (57, 58); therefore, we cannot dismiss the idea of the role of ER $\alpha$ in the PR-cSrc interaction. 
Phosphorylation of $\mathrm{PR}$ is a post-translational modification broadly studied. Among other functions, it is directly related to regulating the transcriptional activity of this receptor and the degradation by the proteasome $(59,60)$. Serine and threonine phosphorylation of PR has been widely investigated (60-62); however, there are no reports about PR tyrosine phosphorylation. Therefore, we performed an in silico analysis in three databases to search putative phosphorylation sites of cSrc over PR. NetPhos 3.1, KinasePhos, and GPS 5.0. predicted the putative tyrosine residue in the amino acid 87 with the highest score. Even when in vitro and in vivo experiments are mandatory to demonstrate this prediction, we can speculate about this post-translational modification's possible role. The phosphorylation of the estrogen receptor by SFKs proteins has been studied in breast cancer cell lines. Its inhibition reduces its stability and transcriptional activity and alters the ligand binding (63).

Then, the interaction of PR and cSrc in glioblastoma cells could be bilateral and involve the genomic and non-genomic actions of P4. In conclusion, this work is the first report in demonstrating the interaction between $\mathrm{cSrc}$ and $\mathrm{PR}$ in human glioblastoma cells. This interaction induces cSrc activation, which in turn participates in the regulation of the activity of proteins involved in the migration and invasion of glioblastomas. The results presented here open new perspectives for the treatment of glioblastomas.

\section{DATA AVAILABILITY STATEMENT}

Publicly available datasets were analyzed in this study. This data can be found here: https://portal.gdc.cancer.gov/

\section{REFERENCES}

1. Louis DN, Perry A, Reifenberger G, von Deimling A, Figarella-Branger D, Cavenee WK, et al. The 2016 World Health Organization Classification of Tumors of the Central Nervous System: a summary. Acta Neuropathol (2016) 131:803-20. doi: 10.1007/s00401-016-1545-1

2. Wen PY, Kesari S. Malignant Gliomas in Adults. N Engl J Med (2008) 359:492-507. doi: 10.1056/NEJMra0708126

3. Matteoni S, Abbruzzese C, Villani V, Malorni W, Pace A, Matarrese P, et al. The influence of patient sex on clinical approaches to malignant glioma. Cancer Lett (2020) 468:41-7. doi: 10.1016/j.canlet.2019.10.012

4. Taylor JW, Dietrich J, Gerstner ER, Norden AD, Rinne ML, Cahill DP, et al. Phase 2 study of bosutinib, a Src inhibitor, in adults with recurrent glioblastoma. J Neurooncol (2015) 121:557-63. doi: 10.1007/s11060-014$1667-\mathrm{z}$

5. Gerstner ER, Batchelor TT. Antiangiogenic therapy for glioblastoma. Cancer J (2012) 18:45-50. doi: 10.1097/PPO.0b013e3182431c6f

6. Chen J, Li Y, Yu TS, McKay RM, Burns DK, Kernie SG, et al. A restricted cell population propagates glioblastoma growth after chemotherapy. Nature (2012) 488:522-6. doi: 10.1038/nature11287

7. Liu CA, Chang CY, Hsueh KW, Su HL, Chiou TW, Lin SZ, et al. Migration/ invasion of malignant gliomas and implications for therapeutic treatment. Int J Mol Sci (2018) 19:1115. doi: 10.3390/ijms19041115

8. Lewis-Tuffin LJ, Feathers R, Hari P, Durand N, Li Z, Rodriguez FJ, et al. Src family kinases differentially influence glioma growth and motility. Mol Oncol (2015) 9:1783-98. doi: 10.1016/j.molonc.2015.06.001

\section{AUTHOR CONTRIBUTIONS}

All authors contributed to the study conception and design. Material preparation, data collection, and analysis were performed by $\mathrm{CB}-\mathrm{A}$ and $\mathrm{AD}-\mathrm{M}$. The first draft of the manuscript was written by $\mathrm{CB}-\mathrm{A}$ and $\mathrm{AD}-\mathrm{M}$ and reviewed by IC-A. AG-A participated in the analysis of results, and all authors commented the versions of the manuscript. All authors contributed to the article and approved the submitted version.

\section{FUNDING}

This work was financially supported by DGAPA-PAPIIT (IN217120), UNAM, Mexico and by a scholarship to CB-A from Consejo Nacional de Ciencia y Tecnología (277679), Mexico.

\section{ACKNOWLEDGMENTS}

The authors thank Carmen J. Zamora-Sánchez (Facultad de Química, UNAM) and Ángela Patricia Moreno-Londoño (Facultad de Medicina, UNAM), for their technical assistance.

\section{SUPPLEMENTARY MATERIAL}

The Supplementary Material for this article can be found online at: https://www.frontiersin.org/articles/10.3389/fendo.2021.640298/ full\#supplementary-material

9. Yang M, Li Y, Chilukuri K, Brady OA, Boulos MI, Kappes JC, et al. L1 stimulation of human glioma cell motility correlates with FAK activation NIH Public Access. J Neurooncol (2011) 105:27-44. doi: 10.1007/s11060-011-0557-x

10. Sun LH, Yang FQ, Zhang CB, Wu YP, Liang JS, Jin S, et al. Overexpression of Paxillin Correlates with Tumor Progression and Predicts Poor Survival in Glioblastoma. CNS Neurosci Ther (2017) 23:69-75. doi: 10.1111/cns.12606

11. Chen Z, Morales JE, Guerrero PA, Sun H, McCarty JH. PTPN12/PTP-PEST regulates phosphorylation-dependent ubiquitination and stability of focal adhesion substrates in invasive glioblastoma cells. Cancer Res (2018) 78:3809-22. doi: 10.1158/0008-5472.CAN-18-0085

12. Maziveyi M, Alahari SK. Cell matrix adhesions in cancer: The proteins that form the glue(2017). Available at: www.impactjournals.com/oncotarget (Accessed October 20, 2020). doi: 10.18632/oncotarget.17265

13. Kobayashi K, Takahashi H, Inoue A, Harada H, Toshimori S, Kobayashi Y, et al. Oct-3/4 promotes migration and invasion of glioblastoma cells. J Cell Biochem (2012) 113:508-17. doi: 10.1002/jcb.23374

14. Ostrom QT, Gittleman H, Truitt G, Boscia A, Kruchko C, Barnholtz-Sloan JS, et al. CBTRUS Statistical Report: Primary Brain and Other Central Nervous System Tumors Diagnosed in the United States in 2011-2015 Introduction. Neuro Oncol (2018) 20:1-86. doi: 10.1093/neuonc/noy131

15. Germán-Castelán L, Manjarrez-Marmolejo J, González-Arenas A, GonzálezMorán MG, Camacho-Arroyo I. Progesterone induces the growth and infiltration of human astrocytoma cells implanted in the cerebral cortex of the rat. BioMed Res Int (2014) 2014:393174. doi: 10.1155/2014/393174

16. Germán-Castelán L, Manjarrez-Marmolejo J, González-Arenas A, CamachoArroyo I. Intracellular Progesterone Receptor Mediates the Increase in 
Glioblastoma Growth Induced by Progesterone in the Rat Brain. Arch Med Res (2016) 47:419-26. doi: 10.1016/j.arcmed.2016.10.002

17. Piña-Medina AG, Hansberg-Pastor V, González-Arenas A, Cerbón M, Camacho-Arroyo I. Progesterone promotes cell migration, invasion and cofilin activation in human astrocytoma cells. Steroids (2016) 105:19-25. doi: 10.1016/j.steroids.2015.11.008

18. Camacho-Arroyo I, Hansberg-Pastor V, Vázquez-Martínez ER, Cerbón M. Mechanism of Progesterone Action in the Brain. In: Hormones, Brain and Behavior. Oxford: Elsevier. (2017). p. 181-214. doi: 10.1016/b978-0-12803592-4.00053-5

19. Fu XD, Goglia L, Sanchez AM, Flamini M, Giretti MS, Tosi V, et al. Progesterone receptor enhances breast cancer cell motility and invasion via extranuclear activation of focal adhesion kinase. Endocr Relat Cancer (2010) 17:431-43. doi: 10.1677/ERC-09-0258

20. Horwitz KB. The molecular biology of RU486. Is there a role for antiprogestins in the treatment of breast cancer? Endocr Rev (1992) 13:14663. doi: 10.1210/edrv-13-2-146

21. Migliaccio A, Piccolo D, Castoria G, Di Domenico M, Bilancio A, Lombardi $\mathrm{M}$, et al. Activation of the Src/p21(ras)/Erk pathway by progesterone receptor via cross-talk with estrogen receptor. EMBO J (1998) 17:2008-18. doi: 10.1093/emboj/17.7.2008

22. Boonyaratanakornkit V, Scott MP, Ribon V, Sherman L, Anderson SM, Maller JL, et al. Progesterone receptor contains a proline-rich motif that directly interacts with $\mathrm{SH} 3$ domains and activates c-Src family tyrosine kinases. Mol Cell (2001) 8:269-80. doi: 10.1016/S1097-2765(01)00304-5

23. Ballaré C, Uhrig M, Bechtold T, Sancho E, Di Domenico M, Migliaccio A, et al. Two Domains of the Progesterone Receptor Interact with the Estrogen Receptor and Are Required for Progesterone Activation of the c-Src/Erk Pathway in Mammalian Cells. Mol Cell Biol (2003) 23:1994-2008. doi: $10.1128 / \mathrm{mcb} .23 .6 .1994-2008.2003$

24. González-Orozco JC, Hansberg-Pastor V, Valadez-Cosmes P, Nicolas-Ortega W, Bastida-Beristain Y, La Fuente-Granada MD, et al. Activation of membrane progesterone receptor-alpha increases proliferation, migration, and invasion of human glioblastoma cells. Mol Cell Endocrinol (2018) 477:81-9. doi: 10.1016/j.mce.2018.06.004

25. González-Orozco JC, Camacho-Arroyo I. Progesterone actions during central nervous system development. Front Neurosci (2019) 13:503. doi: 10.3389/ fnins. 2019.00503

26. Keightley DD. The binding of progesterone, R-5020 and ORG-2058 to progesterone receptor. Eur J Cancer (1979) 15:785-90. doi: 10.1016/00142964(79)90154-3

27. Lin AL, McGill HC, Shain SA. Hormone receptors of the baboon cardiovascular system. Biochemical characterization of aortic and myocardial cytoplasmic progesterone receptors. Circ Res (1982) 50:610-6. doi: 10.1161/01.RES.50.5.610

28. Miller WR, Telford J, Hawkins RA. Binding of $[3 \mathrm{H}]$-methyltrienolone (R1881) by human breast cancers. Eur J Cancer Clin Oncol (1983) 19:14738. doi: 10.1016/0277-5379(93)90018-Z

29. Frame MC. Src in cancer: Deregulation and consequences for cell behaviour. Biochim Biophys Acta - Rev Cancer (2002) 1602:114-30. doi: 10.1016/S0304419X(02)00040-9

30. Han X, Zhang W, Yang X, Wheeler CG, Langford CP, Wu L, et al. The role of Src family kinases in growth and migration of glioma stem cells. Int J Oncol (2014) 45:302-10. doi: 10.3892/ijo.2014.2432

31. Verhaak RGW, Hoadley KA, Purdom E, Wang V, Qi Y, Wilkerson MD, et al. Integrated Genomic Analysis Identifies Clinically Relevant Subtypes of Glioblastoma Characterized by Abnormalities in PDGFRA, IDH1, EGFR, and NF1. Cancer Cell (2010) 17:98-110. doi: 10.1016/j.ccr.2009.12.020

32. Behnan J, Finocchiaro G, Hanna G. The landscape of the mesenchymal signature in brain tumours. Brain (2019) 142:847-66. doi: 10.1093/brain/awz044

33. Osswald M, Jung E, Sahm F, Solecki G, Venkataramani V, Blaes J, et al. Brain tumour cells interconnect to a functional and resistant network. Nature (2015) 528:93-8. doi: 10.1038/nature16071

34. Jaraíz-Rodríguez M, Tabernero MD, González-Tablas M, Otero A, Orfao A, Medina JM, et al. Stem Cell Reports Ar ticle A Shor t Region of Connexin43 Reduces Human Glioma Stem Cell Migration, Invasion, and Survival through Src, PTEN, and FAK. Stem Cell Rep (2017) 9:451-63. doi: 10.1016/ j.stemcr.2017.06.007
35. Irby RB, Yeatman TJ. Role of Src expression and activation in human cancer. Oncogene (2000) 19:5636-42. doi: 10.1038/sj.onc.1203912

36. Li MY, Peng WH, Wu CH, Chang YM, Lin YL, Chang GD, et al. PTPN3 suppresses lung cancer cell invasiveness by counteracting Src-mediated DAAM1 activation and actin polymerization. Oncogene (2019) 38:7002-16. doi: 10.1038/s41388-019-0948-6

37. Jones RJ, Avizienyte E, Wyke AW, Owens DW, Brunton VG, Frame MC. Elevated c-Src is linked to altered cell-matrix adhesion rather than proliferation in KM12C human colorectal cancer cells. Br J Cancer (2002) 87:1128-35. doi: 10.1038/sj.bjc.6600594

38. Yeatman TJ. A renaissance for SRC. Nat Rev Cancer (2004) 4:470-80. doi: $10.1038 / \mathrm{nrc1} 366$

39. Talamonti MS, Roh MS, Curley SA, Gallick GE. Increase in activity and level of pp60c-src in progressive stages of human colorectal cancer. J Clin Invest (1993) 91:53-60. doi: 10.1172/JCI116200

40. Wang Y, Wu N, Pang B, Tong D, Sun D, Sun H, et al. TRIB1 promotes colorectal cancer cell migration and invasion through activation MMP-2 via FAK/Src and ERK pathways. Oncotarget (2017) 8:47931-42. doi: 10.18632/ oncotarget.18201

41. Martin GS. The hunting of the Src. Nat Rev Mol Cell Biol (2001) 2:467-74. doi: $10.1038 / 35073094$

42. Roche S, Fumagalli S, Courtneidge SA. Requirement for Src family protein tyrosine kinases in G2 for fibroblast cell division. Science (80- ) (1995) 269:1567-9. doi: 10.1126/science.7545311

43. Brunton VG, Ozanne BW, Paraskeva C, Frame MC. A role for epidermal growth factor receptor, c-Src and focal adhesion kinase in an in vitro model for the progression of colon cancer. Oncogene (1997) 14:283-93. doi: 10.1038/ sj.onc. 1200827

44. Eom KY, Cho BJ, Choi EJ, Kim JH, Chie EK, Wu HG, et al. The effect of chemoradiotherapy with SRC tyrosine kinase inhibitor, PP2 and temozolomide on malignant glioma cells in vitro and in vivo. Cancer Res Treat (2016) 48:687-97. doi: 10.4143/crt.2014.320

45. Hsia DA, Mitra SK, Hauck CR, Streblow DN, Nelson JA, Ilic D, et al. Differential regulation of cell motility and invasion by FAK. J Cell Biol (2003) 160:753-67. doi: 10.1083/jcb.200212114

46. Natarajan M, Hecker TP, Gladson CL. FAK signaling in anaplastic astrocytoma and glioblastoma tumors. Cancer J (2003) 9:126-33. doi: 10.1097/00130404-200303000-00008

47. Zaidel-Bar R, Milo R, Kam Z, Geiger B. A paxillin tyrosine phosphorylation switch regulates the assembly and form of cell-matrix adhesions. J Cell Sci (2007) 120:137-48. doi: 10.1242/jcs.03314

48. Shen Y, Schneider G, Cloutier JF, Veillette A, Schaller MD. Direct association of protein-tyrosine phosphatase PTP-PEST with paxillin. J Biol Chem (1998) 273:6474-81. doi: 10.1074/jbc.273.11.6474

49. Shen Y, Lyonst P, Cooley M, Davidson D, Veillette A, Salgiall R, et al. The noncatalytic domain of protein-tyrosine phosphatase-PEST targets paxillin for dephosphorylation in vivo. J Biol Chem (2000) 275:1405-13. doi: 10.1074/ jbc.275.2.1405

50. Sanchez AM, Flamini MI, Genazzani AR, Simoncini T. Effects of progesterone and medroxyprogesterone on actin remodeling and neuronal spine formation. Mol Endocrinol (2013) 27:693-702. doi: 10.1210/me.2012-1278

51. Valadez-Cosmes P, Germán-Castelán L, González-Arenas A, VelascoVelázquez MA, Hansberg-Pastor V, Camacho-Arroyo I. Expression and hormonal regulation of membrane progesterone receptors in human astrocytoma cells. J Steroid Biochem Mol Biol (2015) 154:176-85. doi: 10.1016/j.jsbmb.2015.08.006

52. Del Moral-Morales A, González-Orozco JC, Capetillo-Velázquez JM, PiñaMedina AG, Camacho-Arroyo I. The Role of mPR $\delta$ and mPRe in Human Glioblastoma Cells: Expression, Hormonal Regulation, and Possible Clinical Outcome. Horm Cancer (2020) 11:117-27. doi: 10.1007/s12672-020-00381-7

53. Hurd C, Moudgil VK. Characterization of R5020 and RU486 Binding to Progesterone Receptor from Calf Uterus. Biochemistry (1988) 27:3618-23. doi: 10.1021/bi00410a014

54. Cabrera-Munoz E, Tania Hernandez-Hernandez O, Camacho-Arroyo I. Role of Progesterone in Human Astrocytomas Growth. Curr Top Med Chem (2011) 11:1663-7. doi: 10.2174/156802611796117685

55. Mani SK, Oyola MG. Progesterone signaling mechanisms in brain and behavior. Front Endocrinol (Lausanne) (2012) 3:7. doi: 10.3389/fendo.2012.00007 
56. Boonyaratanakornkit V, McGowan E, Sherman L, Mancini MA, Cheskis BJ, Edwards DP. The role of extranuclear signaling actions of progesterone receptor in mediating progesterone regulation of gene expression and the cell cycle. Mol Endocrinol (2007) 21:359-75. doi: 10.1210/me.2006-0337

57. González-Arenas A, Hansberg-Pastor V, Hernández-Hernández OT, González-García TK, Henderson-Villalpando J, Lemus-Hernández D, et al. Estradiol increases cell growth in human astrocytoma cell lines through ER $\alpha$ activation and its interaction with SRC-1 and SRC-3 coactivators. Biochim Biophys Acta - Mol Cell Res (2012) 1823:379-86. doi: 10.1016/ j.bbamcr.2011.11.004

58. Hernández-Vega AM, Del Moral-Morales A, Zamora-Sánchez CJ, PiñaMedina AG, González-Arenas A, Camacho-Arroyo I. Estradiol Induces Epithelial to Mesenchymal Transition of Human Glioblastoma Cells. Cells (2020) 9:1930. doi: 10.3390/cells9091930

59. Camacho-Arroyo I, Villamar-Cruz O, González-Arenas A, Guerra-Araiza C. Participation of the $26 \mathrm{~S}$ proteasome in the regulation of progesterone receptor concentrations in the rat brain. Neuroendocrinology (2002) 76:267-71. doi: $10.1159 / 000066623$

60. González-Arenas A, Peña-Ortiz MÁ, Hansberg-Pastor V, Marquina-Sánchez B, Baranda-Ávila N, Nava-Castro K, et al. $\mathrm{Pkc} \alpha$ and $\mathrm{pkc} \delta$ activation regulates transcriptional activity and degradation of progesterone receptor in human astrocytoma cells. Endocrinology (2015) 156:1010-22. doi: 10.1210/en.20141137
61. Hagan CR, Daniel AR, Dressing GE, Lange CA. Role of phosphorylation in progesterone receptor signaling and specificity. Mol Cell Endocrinol (2012) 357:43-9. doi: 10.1016/j.mce.2011.09.017

62. Marquina-Sánchez B, González-Jorge J, Hansberg-Pastor V, WegmanOstrosky T, Baranda-Ávila N, Mejía-Pérez S, et al. The interplay between intracellular progesterone receptor and $\mathrm{PKC}$ plays a key role in migration and invasion of human glioblastoma cells. J Steroid Biochem Mol Biol (2017) 172:198-206. doi: 10.1016/j.jsbmb.2016.10.001

63. Cans C, Mangano R, Barilá D, Neubauer G, Superti-Furga G. Nuclear tyrosine phosphorylation: The beginning of a map. Biochem Pharmacol (2000) 60:1203-15. doi: 10.1016/S0006-2952(00)00434-2

Conflict of Interest: The authors declare that the research was conducted in the absence of any commercial or financial relationships that could be construed as a potential conflict of interest.

Copyright (C) 2021 Bello-Alvarez, Moral-Morales, González-Arenas and Camacho-Arroyo. This is an open-access article distributed under the terms of the Creative Commons Attribution License (CC BY). The use, distribution or reproduction in other forums is permitted, provided the original author(s) and the copyright owner(s) are credited and that the original publication in this journal is cited, in accordance with accepted academic practice. No use, distribution or reproduction is permitted which does not comply with these terms. 